\title{
ADAPTATIONS OF THE HOODED CROW (CORVUS CORNIX LINNAEUS, 1758) TO URBAN ENVIRONMENT
}

(C) 2019

\author{
Korotkova Tatyana Borisovna, postgraduate student of Biology Department \\ Poddubnaya Nadezhda Yakovlevna, candidate of biological sciences, \\ leading researcher of Ecological-Analytical Laboratory of Biology Department \\ Cherepovets State University (Cherepovets, Vologda Region, Russian Federation)
}

Abstract. The crow birds are an inalienable component of anthropogenic ecosystems and the most successful species is the hooded crow. The success of a species depends on the conformity of a speed of adaptation process to the change rate in the environment. Organisms, adapting to the new environmental parameters in the city, demonstrate adaptive mechanisms, and can be a model for studying the evolutionary process. The process of urbanization of the hooded crow continues at present in many parts of its range, but the causes and mechanisms of these processes are not fully understood. The tasks of our research included finding out the directions and rates of the hooded crow adaptations to the changing urban environment. The research was conducted in 1997-2018. In Cherepovets, the hooded crow began to adapt to the urban environment in the late 1950s. The fastest rate of adaptations of the species was observed in the last decade. The main adaptive processes of the hooded crow in the urban system were the following: 1) territorial changes - occur at different rates, following changes in the urban development of residential buildings and in the age composition of trees, as well as changes in the culture of household waste collection service; 2) changes in the habitats of the hooded crow - are the increase in the tree species used for nesting and changes in the height of the nests, and occur during the last 15 years; 3) changes in seasonal life - in Cherepovets, hooded crows begin breeding 2 weeks earlier than in the vicinity; 4) changes in trophic links - increasing the proportion of anthropogenic feed in the diet of hooded crows as Cherepovets develops; 5) ethological changes - hooded crows became less careful at the end of the 1990s and have learned the skills of extracting food from different packages, cleaning contaminated food and dry food maceration.

Keywords: hodded crow; Corvus cornix; corvids; Corvidae; urbanization; synanthropism; synurbization; adaptive processes; adaptation; anthropogenic factors; urban environment; urban ecosystem; formation of adaptations; territorial changes; ethological changes.

УДК 574.58

DOI 10.24411/2309-4370-2019-11108

Статья поступила в редакцию 08.01.2019

\section{ГИДРОБИОЦЕНОЗЫ ОЗЕРА ТУЛОС (ЮГО-ЗАПАДНАЯ КАРЕЛИЯ)}

(C) 2019

Кучко Ярослав Александрович, кандидат биологических наук, старший научный сотрудник лаборатории экологии рыб и водных беспозвоночных

Ильмаст Николай Викторович, доктор биологических наук, заведующий лабораторией экологии рыб и водных беспозвоночных

Институт биологии Карельского научного центра РАН (2. Петрозаводск, Российская Федерация)

Кучко Тамара Юрьевна, кандидат биологических наук, доцент кафедры зоологии и экологии

Петрозаводский государственный университет (2. Петрозаводск, Российская Федерация)

Аннотация. Проведена инвентаризация современного состояния сообществ фито-, зоопланктона и бентоса озера Тулос, которое благодаря своему географическому положению входит в состав Зеленого пояса Фенноскандии и находится на территории планируемого национального парка «Тулос». Изучены видовое разнообразие, соотношение основных таксономических групп, структура доминирующих видов гидробионтов, их численность и биомасса в литоральной и пелагической частях озера. Согласно полученным результатам (уровень количественного развития и соотношение видов фитопланктона в вегетационный период 2018 года), воды озера Тулос можно отнести к третьему классу качества, разряду 3а («достаточно чистая»), что соответствует $\beta$-мезосапробный зоне по шкале сапробности. По показателю индекса сапробности Пантле-Букк, рассчитанного по зоопланктону, воды озера можно отнести к олигосапробным - 2-й класс качества, чистые природные воды. Показатели обилия макрозообентоса соответствуют олиготрофному классу, по соотношению его основных групп озеро относится к «хирономидному» типу озер. Озеро обладает высоким рекреационным потенциалом, по составу ихтиофауны относится к водоемам первой рыбохозяйственной категории. Озеро Тулос можно рассматривать в качестве удобного контрольного объекта при мониторинге состояния окружающей среды на приграничных территориях.

Ключевые слова: Республика Карелия; озеро Тулос; национальный парк; особо охраняемые природные территории; Зеленый пояс Фенноскандии; мониторинг; экосистема; гидробиоценоз; фитопланктон; зоопланктон; макрозообентос; видовое разнообразие; численность; биомасса; сапробность; трофический статус.

\section{Введение}

Озеро Тулос расположено в западной части Муезерского района Республики Карелия, географиче- ские координаты центра озера $63^{\circ} 34^{\prime}$ с.ш., 30³6' в.д. [1]. Находится на водосборе р. Тула (Лужма) - притока р. Лендерка (бассейн Балтийского моря) на тер- 
Кучко Я.А., Ильмаст Н.В., Кучко Т.Ю.

03.02.00 - общая биология

ритории планируемого национального парка «Тулос», расположенного на границе с Финляндией [2]. Озеро, вследствие географического положения, входит в состав Зеленого пояса Фенноскандии, который протянулся по обе стороны границы трех соседних государств - России, Финляндии и Норвегии [3].

Водоем мало изучен с гидробиологической точки зрения. Имеющиеся данные относятся к осеннему периоду 1997 г., когда рядом научных организаций выполнялись работы по инвентаризации и экологической оценке территории планируемого национального парка $[2 ; 4]$. Озеро находится за линией пограничных инженерно-технических сооружений, доступ на него ограничен и контролируется пограничниками. Постоянного населения на этой территории нет.

Целью исследования являлась оценка современного состояния сообществ фито-, зоопланктона и бентоса озера Тулос.

\section{Mamepuas \\ и методы исследования}

Комплексные гидробиологические исследования проводились на озере Тулос в июле-августе 2018 г. По происхождению котловины озеро относится к ледниково-тектоническим, берега его в основном каменисто-песчаные, водообмен замедленный 0,39 год $^{-1}$. На всей площади водного зеркала расположено более 140 островов. По химическим показателям озеро Тулос относится к типичным водным объектам республики ( $\mathrm{pH} 6,6$, общая минерализация 9,5 мг/л, содержание $\mathrm{CO}_{2}$ в среднем около 1,7 мг/л), насыщение кислородом составляет около 90\%. Характеризуется низким содержанием $\mathrm{P}_{\text {общ. }}$ (7-13 мкг/л) и по его концентрации относится к олиготрофному типу. Общая площадь 95,7 км², средняя глубина 9,4 м, наибольшая 23,5 м [5].

Пробы фито-, зоопланктона и бентоса отбирались на восьми гидробиологических станциях, выбор которых обусловливался морфометрическими особенностями водоема, отдельно обследовались прибрежная (литораль) и центральная (пелагиаль) части. Планктонные пробы отбирались с трехкратной повторностью: в пелагиали - батометром Руттнера (объем 2 л), в литорали - мерным ведром (на глубинах до 1,0 м). Водоросли концентрировались осадочным методом при помощи мембранных фильтров (диаметр пор 0,95-1,02 мкм), пробы зоопланктона процеживались с использованием планктонной сети (диаметр ячеи 90 мкм). Дальнейшая обработка проб проводилась согласно общепринятым гидробиологическим методикам [6-8]. Качество воды оценивалось методом Пантле-Букк в модификации Сладечека [911] и в соответствии с эколого-санитарной классификацией [12]. Количественные пробы макрозообентоса отбирались дночерпателем ДАК-250 модификации Экмана-Берджа (площадь захвата 1/40 м².), промывались через сито № 19 (размер ячеи 0,5 мм) и фиксировались $8 \%$ раствором формальдегида. На каждой станции отбиралось по 2 дночерпателя. Для обработки проб также применялись стандартные методики [13].

Трофический статус водоема оценивался по шкале трофности по С.П. Китаеву [14]. При определении организмов использовался ряд руководств [15; 16].

Гидробиоценозы озера Тулос (Юго-Западная Карелия)

\section{Результаты и обсуждение}

В рамках данной работы в озере в фитопланктоне о3. Тулос обнаружено 23 вида водорослей 6 систематических групп: золотистые (Chrysophyta) - 1 (4\%), эвгленовые (Euglenophyta) - 2 (9\%), синезеленые (Cyanophyta) - 2 (9\%), зеленые (Chlorophyta) $3(13 \%)$, динофитовые (Dinophyta) - $3(13 \%)$ и диатомовые (Bacillariophyta) - 12 (52\%) (табл. 1). Наиболее разнообразно представлены диатомовые водоросли, что характерно для альгофлоры планктона разнотипных водоемов Северо-Запада Европейской части России, Арктики и Субарктики [17; 18$]$.

Таблица 1 - Видовой состав фитопланктона оз. Тулос

\begin{tabular}{|c|c|c|}
\hline Отдел / Таксон & $\begin{array}{l}\text { Лито- } \\
\text { раль }\end{array}$ & $\begin{array}{l}\text { Пела- } \\
\text { гиаль }\end{array}$ \\
\hline \multicolumn{3}{|c|}{ Синезеленые (Cyanophyta) } \\
\hline Oscillatoria limosa (Dilv.) Ag. & + & + \\
\hline Chroococcus giganteus West. & + & + \\
\hline \multicolumn{3}{|c|}{ Диатомовые (Bacillariophyta) } \\
\hline Aulacoseira islandica Ehr. & + & + \\
\hline $\begin{array}{l}\text { Aulacoseira italica } \\
\text { var. tenuissima } \text { Ehr. }\end{array}$ & + & + \\
\hline Tabellaria fenestrata (Lyngb.) Kütz. & + & + \\
\hline Tabellaria flocculosa (Roth.) Kütz. & + & - \\
\hline Cyclotella planctonica Brunnthaler & + & + \\
\hline $\begin{array}{l}\text { Cymbella cymbiformis (Kütz.) V.H. } \\
\text { var. cymbiformis }\end{array}$ & + & - \\
\hline $\begin{array}{l}\text { Cymbella helvetica Kütz. } \\
\text { var. helvetica }\end{array}$ & + & - \\
\hline $\begin{array}{l}\text { Gomphonema acuminatum } \\
\text { Ehrenberg }\end{array}$ & + & + \\
\hline Fragilaria crotonensis Kitton & + & - \\
\hline Navicula Kütz. var. cryptocephala & + & - \\
\hline Navicula radiosa Kütz. var. radiosa & + & + \\
\hline $\begin{array}{l}\text { Eunotia pectinalis (Dillw.) Rabenh. } \\
\text { var. pectinalis }\end{array}$ & + & - \\
\hline
\end{tabular}

Золотистые (Chrysophyta)

\begin{tabular}{|l|l|l}
\hline Dinobryon divergens $\mathrm{Imh}$. & + & +
\end{tabular}

Зеленые (Chlorophyta)

\begin{tabular}{|l|c|c|}
\hline Chlamydomonas monadina Stein. & + & + \\
\hline Cosmarium phaseolum Breb. & + & + \\
\hline Euastrum ansatum Ehrenberg & + & + \\
\hline
\end{tabular}

Динофитовые (Dinophyta)

\begin{tabular}{|l|c|c|}
\hline $\begin{array}{l}\text { Glenodinium quadridens } \\
\text { (Stein.) Sch. }\end{array}$ & - & + \\
\hline Peridinium goslaviense Wolosz. & + & + \\
\hline $\begin{array}{l}\text { Ceratium hirundinella } \\
\text { (O.F.M.) Bergh. }\end{array}$ & + & - \\
\hline
\end{tabular}

\section{Эвгленовые (Euglenophyta)}

\begin{tabular}{|l|c|c|}
\hline Trachelomonas rugulosa Stein. & - & + \\
\hline $\begin{array}{l}\text { Trachelomonas hispida } \\
\text { (Perty) Stein emend. Defl. }\end{array}$ & - & + \\
\hline \multicolumn{1}{|c|}{ Суммарное число видов } & 20 & 16 \\
\hline
\end{tabular}


Кучко Я.А., Ильмаст Н.В., Кучко Т.Ю.

Среди диатомовых доминировали Aulacoseira islandica, A. italica var. tenuissima и Stephanodiscus agassizensis, среди зеленых преобладали Cosmarium phaseolum и Euastrum ansatum. Динофитовые водоросли были представлены Glenodinium guadridens, Ceratium hirundinella и Peridinium goslaviense.

В литоральной и пелагических частях водоема наблюдаются различия в соотношении числа видов по систематическим отделам водорослей (табл. 1). Повышенное видовое разнообразие планктонных водорослей в прибрежье по сравнению с центральной частью водоема может быть обусловлено наличием «краевого эффекта» с большим разнообразием экологических ниш. К числу массовых в литорали относились виды рода Aulacoseira, в пелагиали - представители рода Trachelomonas и Glenodinium guadridens.
Показатели обилия фитопланктона приводятся в таблице 2. В прибрежной части фитопланктонное сообщество большей частью представлено диатомовыми водорослями (виды родов Aulocoseira, Tabellaria, Navicula). На их долю приходится $70 \%$ от общей численности и $48 \%$ биомассы всех водорослей. В пелагиали также преобладают диатомовые водоросли (62\% и 42\% по численности и биомассе соответственно), к субдоминантам относятся представители динофитовых и эвгленовых водорослей (Glenodinium quadridens, Trachelomonas rugulosa, T. Hispi$d a)$. Суммарные показатели численности фитопланктона в литорали и пелагиали озера Тулос составляют соответственно 135,0 тыс. кл/л и 119,0 тыс. кл/л,

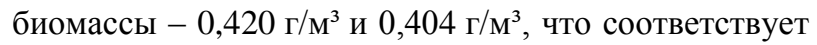
олиготрофному типу водоема по шкале трофности.

таблица 2 - Количественные показатели фитопланктона оз. Тулос

\begin{tabular}{|c|c|c|c|c|c|c|c|c|}
\hline \multirow{3}{*}{ Отдел } & \multicolumn{4}{|c|}{ Литораль } & \multicolumn{4}{|c|}{ Пелагиаль } \\
\hline & \multicolumn{2}{|c|}{ Численность } & \multicolumn{2}{|c|}{ Биомасса } & \multicolumn{2}{|c|}{ Численность } & \multicolumn{2}{|c|}{ Биомасса } \\
\hline & $\begin{array}{c}\text { абс., } \\
\text { тыс. кл/л }\end{array}$ & $\begin{array}{c}\text { отн., } \\
\%\end{array}$ & $\begin{array}{l}\text { абс., } \\
\Gamma / \mathrm{M}^{3}\end{array}$ & $\begin{array}{c}\text { отн., } \\
\%\end{array}$ & $\begin{array}{c}\text { абс., } \\
\text { тыс. кл/л }\end{array}$ & $\begin{array}{c}\text { отн., } \\
\%\end{array}$ & $\begin{array}{l}\text { абс., } \\
\Gamma / \mathrm{M}^{3}\end{array}$ & $\begin{array}{c}\text { отн., } \\
\%\end{array}$ \\
\hline Bacillariophyta & 94,5 & 70 & 0,202 & 48 & 73,8 & 62 & 0,170 & 42 \\
\hline Chrysophyta & 2,7 & 2 & 0,004 & 1 & 1,2 & 1 & 0,004 & 1 \\
\hline Chlorophyta & 4,0 & 3 & 0,021 & 5 & 2,4 & 2 & 0,004 & 1 \\
\hline Cyanophyta & 18,9 & 14 & 0,034 & 8 & 9,5 & 8 & 0,008 & 2 \\
\hline Dinophyta & 4,1 & 3 & 0,088 & 21 & 11,9 & 10 & 0,125 & 31 \\
\hline Euglenophyta & 10,8 & 8 & 0,071 & 17 & 20,2 & 17 & 0,093 & 23 \\
\hline Всего & 135,0 & 100 & 0,42 & 100 & 119,0 & 100 & 0,404 & 100 \\
\hline
\end{tabular}

Показатели индекса сапробности, рассчитанные по численности индикаторных видов фитопланктона ( $\mathrm{S}=1,74$ для литорали и $\mathrm{S}=1,70$ для пелагиали), позволяют отнести воды озера к третьему классу качества, разряду 3 а («достаточно чистая»), что соответствует $\beta$-мезосапробный зоне по шкале сапробности.

В составе зоопланктона оз. Тулос отмечены представители 26 видов ракообразных и коловраток, относящихся к 9 отрядам. Среди них: Copepoda - 7 видов, Cladocera - 12 видов и Rotifera -7 видов (табл. 3).

В целом планктонный комплекс оз. Тулос представлен обычными обитателями северных водоемов. Наибольшей численностью среди коловраток характеризуются Asplanchna priodonta, Kellicottia longispina и Conochilus unicornis. В небольших количествах, но повсеместно встречаются Bipalpus hudsoni и Keratella cochlearis.

Основную долю пелагического планктонного комплекса ракообразных составляют представители северной фауны, которые широко распространены в карельских озерах (Daphnia cristata, Bosmina coregoni, Holopedium gibberum, Thermocyclops oithonoides, Eudiaptomus gracilis) и ряд эвритопных организмов с широкой экологической валентностью (Mesocyclops leuckarti, Bosmina longirostris, Chydorus sphaericus). В литоральной зоне, несмотря на слабое развитие высшей водной растительности (тростник обыкновенный, кубышка желтая, рдесты), достаточно широко представлены фитофильные и придонно-бентические формы. В основном это Sida crystallina и Scapholeberis mucronata, которым необходим субстрат для периодического прикрепления, а также хидориды и хищные циклопы. В таблице 4 представлены структурные показатели зоопланктонного сообщества, используемые в качестве индикаторных при экологических исследованиях водоемов. Отсутствие резкого доминирования отдельных видов обусловило достаточно высокие значения индекса видового разнообразия Шеннона, что указывает на хорошие условия для развития зоопланктоценозов водоема. По уровню количественного развития зоопланктона озеро Тулос в целом можно охарактеризовать как олиготрофный водоем (показатель

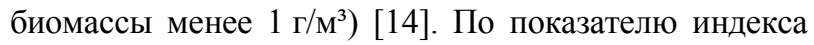
сапробности Пантле-Букк, рассчитанного по зоопланктону, воды озера можно отнести к олигосапробному классу (2-й класс качества, чистые природные воды). 
Кучко Я.А., Ильмаст Н.В., Кучко Т.Ю.

03.02.00 - общая биология

Таблица 3 - Видовой состав и встречаемость видов зоопланктона оз. Тулос

\begin{tabular}{|c|c|c|}
\hline Отряд / Таксон & $\begin{array}{c}\text { Лито- } \\
\text { раль }\end{array}$ & $\begin{array}{l}\text { Пела- } \\
\text { гиаль }\end{array}$ \\
\hline \multicolumn{3}{|l|}{ Коловратки Rotifera } \\
\hline \multicolumn{3}{|l|}{ Отряд Saeptiramida } \\
\hline Polyarthra dolychoptera Idelson & + & - \\
\hline Bipalpus hudsoni (Imhof) & ++ & ++ \\
\hline \multicolumn{3}{|l|}{ Отряд Saltiramida } \\
\hline Asplanchna priodonta Gosse & + & +++ \\
\hline \multicolumn{3}{|l|}{ Отряд Transversiramida } \\
\hline Euchlanis dilatata Ehrenberg & + & - \\
\hline Keratella cochlearis (Gosse) & - & + \\
\hline Kellicottia longispina (Kellicott) & +++ & +++ \\
\hline \multicolumn{3}{|l|}{ Отряд Protoramida } \\
\hline Conochilus unicornis Rousselet & + & - \\
\hline \multicolumn{3}{|l|}{$\begin{array}{r}\text { Ракообразные Crustacea } \\
\end{array}$} \\
\hline \multicolumn{3}{|l|}{ Отряд Calaniformes } \\
\hline Heterocope appendiculata (Sars) & - & + \\
\hline Eudiaptomus gracilis (Sars) & ++ & ++ \\
\hline \multicolumn{3}{|l|}{ Отряд Cyclopiformes } \\
\hline Macrocyclops albidus (Jurine) & $*$ & - \\
\hline Thermocyclops oithonoides (Sars) & +++ & +++ \\
\hline Mesocyclops leuckarti (Claus) & +++ & +++ \\
\hline Megacyclops viridis (Jurine) & $*$ & - \\
\hline Cyclops strenuus strenuus Fisher & + & + \\
\hline \multicolumn{3}{|l|}{ Класс Branchiopoda } \\
\hline \multicolumn{3}{|l|}{ Надотряд Cladocera } \\
\hline \multicolumn{3}{|l|}{ Отряд Ctenopoda } \\
\hline Syda crystallina (O.F. Muller, 1776) & +++ & - \\
\hline Limnosida frontosa Sars, 1862 & - & ++ \\
\hline \multicolumn{3}{|l|}{ Отряд Anomopoda } \\
\hline Daphnia cristata Sars & + & +++ \\
\hline Ceriodaphnia quadrangula (O.F. Muller) & ++ & ++ \\
\hline Alona quadrangularis (O.F. Muller) & + & - \\
\hline Acroperus harpae (Baird) & + & - \\
\hline Scapholeberis mucronata (O.F. Muller) & ++ & $*$ \\
\hline Chydorus sphaericus (O.F. Muller) & + & + \\
\hline Eurycercus lamellatus (O.F. Muller) & $*$ & - \\
\hline $\begin{array}{l}\text { Bosmina (Bosmina) longirostris } \\
\text { (O.F. Muller) }\end{array}$ & +++ & +++ \\
\hline B. (Eubosmina) coregoni Baird, 1857 & ++ & ++ \\
\hline \multicolumn{3}{|l|}{ Отряд Onychopoda } \\
\hline Polyphemus pediculus (Linne) & + & - \\
\hline Суммарное число видов & 23 & 16 \\
\hline
\end{tabular}

Примечание. Встречаемость: +++ - вид широко распространен (>50\% проб); ++ - вид обычен (25$50 \%$ проб); + - вид редок $(<25 \%$ проб); * - единичные находки.

Донная фауна оз. Тулос была представлена 7 таксономическими группами (табл. 5). Преобладающими организмами по численности и по величине биомассы являлись личинки хирономид (Procladius sp., Sergentia sp., Lauterbornia coracina). Олигохеты занимали субдоминирующее положение, на отдельных станциях встречались двустворчатые и брюхоногие моллюски. Таким образом, по составу макрозообентоса озеро можно отнести к «хирономидному» типу озер. В осенний период средняя биомасса зообентоса в озере при средней численности организмов

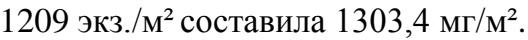

Гидробиоценозы озера Тулос (Юго-Западная Карелия)

таблица 4 - Структурные показатели зоопланктона оз. Тулос

\begin{tabular}{|c|c|c|}
\hline Показатель & Литораль & Пелагиаль \\
\hline $\begin{array}{l}\text { Общее число видов } \\
\text { Sобщ. }\end{array}$ & 23 & 16 \\
\hline $\begin{array}{l}\text { Число видов } \\
\text { в пробе Sпр. }\end{array}$ & $12,3 \pm 1,2$ & $10,6 \pm 1,1$ \\
\hline $\begin{array}{l}\text { Индекс Шеннона } \\
\left(H_{N}\right), \text { бит/экз. }\end{array}$ & $2,72 \pm 0,33$ & $2,90 \pm 0,35$ \\
\hline $\begin{array}{l}\text { Индекс доминиро- } \\
\text { вания Бергера- } \\
\text { Паркера } I_{B / P}\end{array}$ & $0,37 \pm 0,10$ & $0,40 \pm 0,12$ \\
\hline $\begin{array}{l}\text { Средняя числ-ть } \\
\text { (min-max), } \\
\text { тыс. экз./Mㄹ }\end{array}$ & $\begin{array}{c}10,29 \\
(3,21-26,75)\end{array}$ & $\begin{array}{c}5,44 \\
(4,1-6,7)\end{array}$ \\
\hline $\begin{array}{l}\text { Средняя биомасса } \\
(\min -\max ), \Gamma / \mathrm{M}^{3}\end{array}$ & $\begin{array}{c}0,368 \\
(0,122-0,504) \\
\end{array}$ & $\begin{array}{c}0,138 \\
(0,093-0,188) \\
\end{array}$ \\
\hline $\begin{array}{l}\text { Индекс сапробно- } \\
\text { сти Пантле-Букк }\end{array}$ & $1,83 \pm 0,22$ & $1,72 \pm 0,14$ \\
\hline $\begin{array}{l}\text { Доминирующий } \\
\text { комплекс }\end{array}$ & $\begin{array}{l}\text { B. longirostris } \\
\text { C. quadrangula } \\
\text { S. mucronata }\end{array}$ & $\begin{array}{c}\text { B. coregoni } \\
\text { D. cristata } \\
\text { B. longirostris }\end{array}$ \\
\hline $\begin{array}{l}\text { Типизация } \\
\text { водоема }\end{array}$ & $\begin{array}{c}\text { олиготрофный } \\
\beta \text { - мезосапро- } \\
\text { бный } \\
\end{array}$ & $\begin{array}{c}\text { олиготроф- } \\
\text { ный } \beta \text { - мезо- } \\
\text { сапробный } \\
\end{array}$ \\
\hline
\end{tabular}

Таблица 5 - Количественные показатели макрозообентоса оз. Тулос

\begin{tabular}{|c|c|c|c|c|}
\hline \multirow[b]{2}{*}{ Таксоны } & \multicolumn{4}{|c|}{ Показатели } \\
\hline & $\begin{array}{c}\text { Числен- } \\
\text { ность, } \\
\text { экз./м² }\end{array}$ & $\%$ & 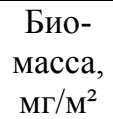 & $\%$ \\
\hline Oligochaeta & 160 & 13,2 & 199,5 & 15,3 \\
\hline Bivalvia & 80 & 6,6 & 58,0 & 4,5 \\
\hline Gastropoda & 22 & 1,9 & 49,0 & 3,7 \\
\hline Ephemeroptera & 4 & 0,3 & 0,6 & 0,1 \\
\hline Trichoptera & 6 & 0,5 & 0,5 & 0,1 \\
\hline Chironomidae & 792 & 65,5 & 976,8 & 74,9 \\
\hline Nematoda & 145 & 12,0 & 19,0 & 1,4 \\
\hline Всего & 1209 & 100,0 & 1303,4 & 100,0 \\
\hline
\end{tabular}

Выводы

Полученные данные позволяют охарактеризовать озеро Тулос как водоем с высоким качеством воды, уровень которого по гидрохимическим и гидробиологическим показателям сопоставим с карельскими водоемами, имеющими различный природоохранный статус, - озерами Каменное, Урозеро, Мунозеро [19-21].

Озеро обладает высоким рекреационным потенциалом, отличается примечательными морфометрическими, гидрохимическими и ихтиологическими показателями, что позволяет рекомендовать создание на его основе единого природоохранного комплекса. Удаленность и труднодоступность района расположения озера, а также отсутствие загрязняющих его водную среду стоков позволяют рассматривать оз. Тулос в качестве удобного контрольного объекта при мониторинге состояния окружающей среды на приграничных территориях. Также необходимо учитывать, что оз. Тулос является сигово-лососевым водоемом и относится к первой категории рыбохозяйственного водопользования. 


\section{Список литературы:}

1. Озера Карелии. Справочник. Петрозаводск: КарНЦ РАН, 2013. 464 c.

2. Инвентаризация и изучение биологического разнообразия в приграничных с Финляндией районах Республики Карелия. Оперативно-информационные материалы. Петрозаводск: КарНЦ РАН, 1998. 168 с.

3. Зеленый пояс Фенноскандии: научно-популярное иллюстрированное издание. Петрозаводск: КарНЦ РАН, 2014. 116 с.

4. Куликова Т.П. Зоопланктон водных объектов северной части бассейна Ладожского озера. Петрозаводск: КарНЦ РАН, 2012. 192 с.

5. Каталог озер Карелии. Петрозаводск: КарНЦ PAH, 2001. $290 \mathrm{c}$

6. Методические рекомендации по сбору и обработке материалов при гидробиологических исследованиях на пресноводных водоемах. Зоопланктон и его продукция. Л.: ГосНИОРХ. 1984. 33 с.

7. Практическая гидробиология. Пресноводные экосистемы. М.: ПИМ, 2006. 367 с.

8. Унифицированные методы исследования качества вод: В 3 ч. Ч. 3. Методы биологического анализа вод. М.: СЭВ, 1976. 185 с.

9. Баринова С.С., Медведева Л.А., Анисимова О.В. Биоразнообразие водорослей-индикаторов окружающей среды. Тель-Авив, Pilies Studio. 2006. 498 с.

10. Макрушин А.В. Биологический анализ качества вод. Л.: Зоологический институт АН СССР, $1974.60 \mathrm{c}$.

11. Sladeček V. System of water quality from biological point of view // Archiv fur Hydrobiologie. 1973. № $7.218 \mathrm{p}$.

12. Оксиюк О.П., Жукинский В.Н., Брагинский Л.П. и др. Комплексная экологическая классификация качества поверхностных вод суши // Гидробиологический журнал. 1993. Т. 29, № 4. С. 62-76.
13. Жадин В.И. Методика изучения донной фауны и экологии донных беспозвоночных // Жизнь пресных вод СССР. Т. 4. Ч. 1. М.; Л., 1956. С. 279382.

14. Китаев С.П. Основы лимнологии для гидробиологов и ихтиологов. Петрозаводск: КарНЦ РАН, 2007. $390 \mathrm{c}$.

15. Определитель пресноводных водорослей CССР: В 14 т. Т. 1-8, 10, 11, 13, 14 / под ред. М.М. Голлербаха. Л.: Наука, 1951. 1986.

16. Определитель зоопланктона и зообентоса пресных вод Европейской России. Т. 1. Зоопланктон. М.: Товарищество научных изданий КМК, 2010. $495 \mathrm{c}$.

17. Гецен М.В. Водоросли в экосистемах Крайнего Севера. Л.: Наука: Ленингр. отд-ние, 1985. 165 с.

18. Sheath R.G., Munavar M. Phytoplankton composition of small subarctic lake during summer // Canadian Journal of Botany. 1975. Vol. 53 (19). P. 2240-2246.

19. Ильмаст Н.В., Китаев С.П., Кучко Я.А., Павловский С.А. Гидроэкология разнотипных озер южной Карелии. Петрозаводск: КарНЦ РАН, 2008. 90 с.

20. Ильмаст Н.В., Стерлигова О.П., Кучко Я.А. Рыбохозяйственное использование малых водоемов Карелии (на примере Урозера) // Озера Евразии: проблемы и пути их решения: мат-лы 1-й междунар. конф. Петрозаводск: Карельский научный центр PAH, 2017. C. 506-510.

21. Кучко Я.А., Кучко Т.Ю., Ильмаст Н.В. Зоопланктон как показатель состояния экосистемы озера Каменное // Ученые записки Петрозаводского государственного университета. 2017. № 6. С. 27-31.

Финансовое обеспечение исследований осуществлялось из средств федерального бюджета на выполнение государственного задания № 02212017-0045, Программы Президиума РАН «Биоразнообразие природных систем и биологические ресурсы России» проект № 0221-2018-0002; проекта РФФИ № 18-04-00163a.

\section{HYDROBIOCENOSES OF LAKE TULOS, SOUTHWESTERN KARELIA}

(C) 2019

Kuchko Yaroslav Aleksandrovich, candidate of biological sciences,

senior researcher of Fish and Water Invertebrate Ecology Laboratory

Ilmast Nikolay Viktorovich, doctor of biological sciences, head of Fish and Water Invertebrate Ecology Laboratory Institute of Biology of Karelian Research Centre of Russian Academy of Sciences

(Petrozavodsk, Russian Federation)

Kuchko Tamara Yuryevna, candidate of biological sciences, associate professor of Zoology and Ecology Department

Petrozavodsk State University (Petrozavodsk, Russian Federation)

Abstract. The following paper assesses the current state of the phyto- and zooplankton and benthic communities of Lake Tulos, which geographically is a part of the Green Belt of Fennoscandia. The lake is located on the territory of the planned National Park «Tulos». The species diversity, the ratio of major taxonomic groups and the structure, abundance and biomass of predominant aquatic organism species in the littoral and pelagic zones of the lake were studied. According to the obtained results (the level of quantitative development and the ratio of phytoplankton species during the growing season 2018) the waters of Lake Tulos can be assigned to the third quality class, grade 3a («fairly clean»), which corresponds to the $\beta$-mesosaprobic zone by the saprobity scale. According to Pantle-Bukk saprobity index calculated on the basis of zooplankton, the lake's water can be attributed to oligosaprobic - the $2^{\text {nd }}$ class of quality, pure natural waters. Indices of abundance of macrozoobenthos correspond to the oligotrophic class, according to the ratio of its main groups, the lake belongs to the «chironomid» type of lakes. The reservoir has a high recreational potential, according to the ichthyofauna composition it belongs to the water bodies of the first fishery category. Lake Tulos is a reference water body convenient for environmental monitoring in near-border areas.

Keywords: Republic of Karelia; Lake Tulos; national park; specially protected natural areas; Green Belt of Fennoscandia; monitoring; ecosystem; hydrobiocenosis; phytoplankton; zooplankton; macrozoobenthos; species diversity; abundance; biomass; saprobity; trophic status. 